\title{
Physical Properties of OSB Panels Manufactured with CCA and CCB Treated Schizolobium amazonicum and Bonded with Castor Oil Based Polyurethane Resin
}

\author{
Fabiane Salles Ferro ${ }^{1}$, Tiago Hendrigo de Almeida ${ }^{1}$, Diego Henrique de Almeida ${ }^{2}$, \\ André Luis Christoforo ${ }^{3, *}$, Francisco Antonio Rocco Lahr ${ }^{4}$ \\ ${ }^{1}$ Department of Science and Material Engineering, Engineering School of São Carlos (SMM), São Carlos, Brazil \\ ${ }^{2}$ Department of Engineering, College Pitágoras, Poços de Caldas, Brazil \\ ${ }^{3}$ Centre for Innovation and Technology in Composites - CIT ${ }^{\mathrm{e}} \mathrm{C}$, Department of Civil Engineering (DECiv), \\ Federal University of São Carlos, São Carlos, Brazil \\ ${ }^{4}$ Department of Structural Engineering (SET), São Paulo University (EESC/USP), São Carlos, Brazil
}

\begin{abstract}
This research aimed to evaluate the physical properties of OSB panels manufactured using Paricá (Schizolobium amazonicum) wood species particles, treated with CCA (chromated copper arsenate) and CCB (chromated copper borate) preservatives, and castor oil based polyurethane resin. Three resin contents were evaluated: 8,10 and $12 \%$. Results showed that OSB panels manufactured with CCA-treated wood particles did not meet the minimum requirements stipulated by EN 300Code, while OSB containing CCB treated wood particles reached the properties values required for structural applications in dry conditions. Therefore, it was demonstrated the feasibility of using CCB-treated Paricá wood and castor oil based polyurethane resin in OSB production.
\end{abstract}

Keywords Schizolobium amazonicum, Oriented strand board (OSB), Treated wood

\section{Introduction}

Oriented Strand Board (OSB) is a wood particleboard of formed by "strands" in oriented layers, bonded with waterproof resin and consolidated under hot pressing. It is an engineered wood product used widely in construction materials such as coating, flooring and I-beams $[1,2]$.

As other wood products, OSB is also subject to decomposition when exposed to favorable conditions do biological decay, imposed by microorganisms such as fungi. In general, OSB has been not used for applications where there is direct contact with moisture sources, such as ground or wet ambient [3].

Preservative treatment application in structural composite panels, as OSB, could be an effective method to prolong their use, which are commonly made of with low natural durability wood. The traditional methods of treatment with water-based preservatives such CCA (chromated copper arsenate) and $\mathrm{CCB}$ (chromated copper borate), which are conducted under high pressure after panel production, has not proved to be effective enough for OSB treatment,

\footnotetext{
* Corresponding author:
}

alchristoforo@gmail.com (André Luis Christoforo)

Published online at http://journal.sapub.org/ijme

Copyright (C) 2016 Scientific \& Academic Publishing. All Rights Reserved because of water has an adverse effect on adhesive bond, resulting in higher thickness swelling and water absorption of these panels [4].

To obtain desirable properties for OSB with preservative treatment, factors as the application stage of treatment, preservative type and their combination with the type of adhesive should be considered [5]. The good interaction between the mentioned factors was verified in studies with composite panels made with treated wood particles bonded with castor oil based polyurethane resin, as Bertolini et al. [6], with homogeneous particles panels manufactured with waste of CCB-treated Pinus sp., Ferro et al. [2] with OSB panels manufactured using CCA and CCB treated Schizolobium amazonicum wood species; Nascimento et al. [7] with high density particleboard manufactured with CCA and CCBtreated Eucalyptus sp.

Considering the positive aspects of the current production of OSB and the need for studies that provide the use of preservative treatment in these panels, the present work aimed to evaluate the physical properties of OSB panels manufactured with CCA and CCB treated Schizolobium amazonicum strands and castor oil based polyurethane resin.

\section{Material and Methods}

Wood species chosen was Paricá (Schizolobium 
amazonicum), due it slow density (about $0.40 \mathrm{~g} / \mathrm{cm}^{3}$ ) and good permeability. Paricá pieces came from a seven years old plantation, located in Paragominas City, Pará State, Brazil, and were treated with CCA salts and CCB oxides (Figure 1a). Retentions adopted were 6.5 and $9.6 \mathrm{~kg}$ of ingredients active $/ \mathrm{m}^{3}$, respectively, as pointed out by several authors $[2,6]$.

Strands were generated with nominal dimensions under $90 \times 35 \times 0.7 \mathrm{~mm}$ (Figure 1c) and dried to achieve moisture content between 10 and $12 \%$, based on dry weight of strands (compatible for convenient bonding reactions). Strands were glued with bi-component castor oil based polyurethane resin, with $100 \%$ solid content, composed by a polyol (component derived from vegetable oil) and a prepolymer (Figure 1b). The ratio of prepolymer and polyol used was 1:1 $[2,8]$.

Three resin contents were evaluated, providing six different experimental conditions, as shown in Table 1. For each experimental condition, four OSB panels were produced with nominal dimensions $40 \times 40 \times 1 \mathrm{~cm}$ and nominal density $0.70 \mathrm{~g} / \mathrm{cm}^{3}$, totaling 24 panels $[2,8,9]$.

Table 1. Experimental program

\begin{tabular}{ccc}
\hline Experimental conditions & Preservative & \% Resin \\
\hline C1 & CCA & 8 \\
C2 & CCA & 10 \\
C3 & CCA & 12 \\
C4 & CCB & 8 \\
C5 & CCB & 10 \\
C6 & CCB & 12 \\
\hline
\end{tabular}

Panels were made with 3 layers. In the surface layers, strands were oriented and, in the middle layer, strands were randomly distributed (Figure 1d and 1e). Strands proportion in the surface/middles layers were 40:60. Mattress of strands was pressed at a temperature of $100^{\circ} \mathrm{C}$ for 10 minutes, and specific pressure of $4 \mathrm{MPa}$ (Figure 1f) [2, 4, 7]. Figure 1 shows the manufactured process of OSB.

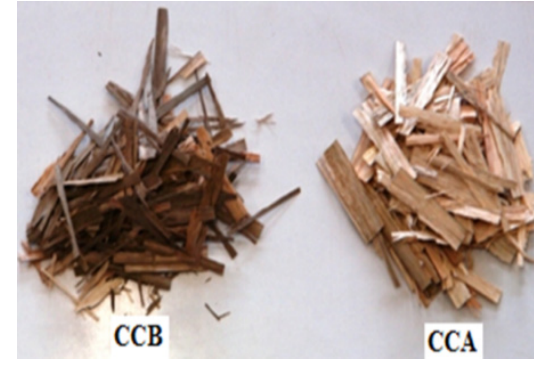

(a)

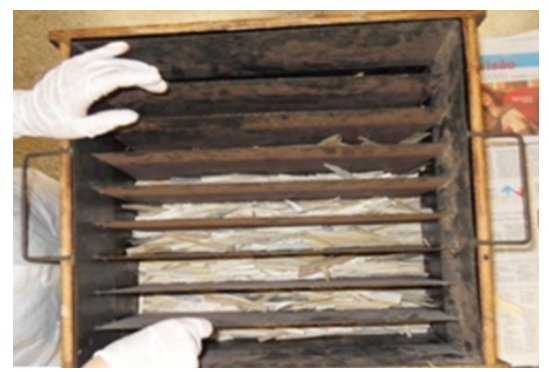

(d)

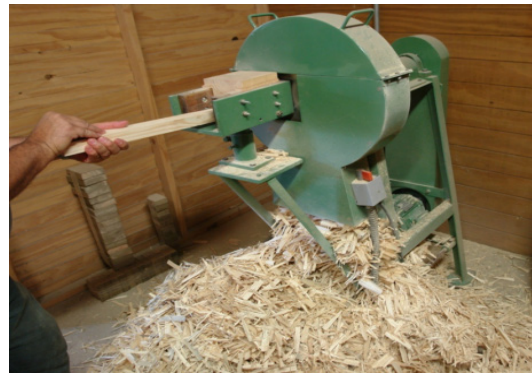

(b)

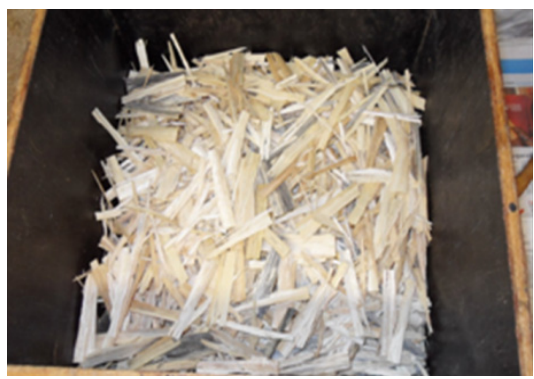

(e)

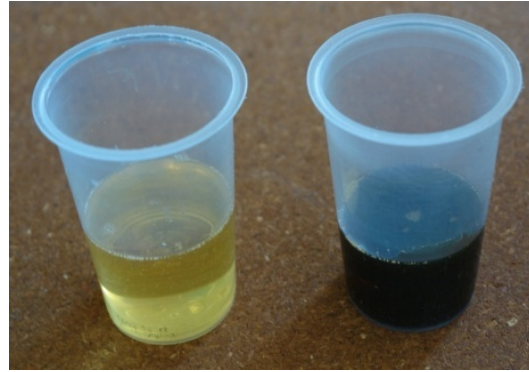

(c)

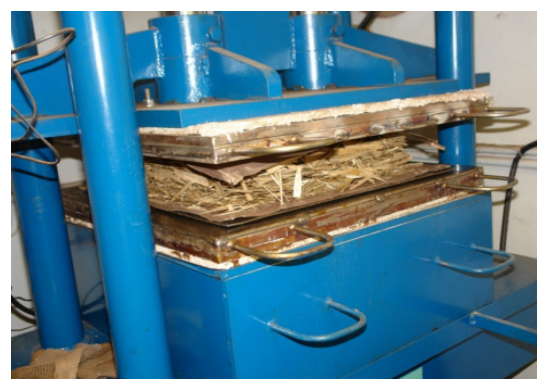

(f)

Figure 1. OSB manufacture process

Table 2. Mean results and coefficient of variation of the physical properties investigated

\begin{tabular}{ccccccccccccc}
\hline \multirow{2}{*}{ EC } & \multicolumn{2}{c}{ Dens } & \multicolumn{2}{c}{ MC } & \multicolumn{2}{c}{ ST2h } & \multicolumn{2}{c}{ ST24h } & \multicolumn{2}{c}{ AA2h } & \multicolumn{2}{c}{ AA24h } \\
& $M$ & $C v(\%)$ & $M$ & $C v(\%)$ & $M$ & $C v(\%)$ & $M$ & $C v(\%)$ & $M$ & $C v(\%)$ & $M$ & $C v(\%)$ \\
\hline $\mathrm{C} 1$ & 0.64 & 3 & 8.22 & 1 & 29.81 & 28 & 41.76 & 22 & 45.18 & 22 & 87.02 & 12 \\
$\mathrm{C} 2$ & 0.64 & 3 & 7.49 & 5 & 20.14 & 28 & 30.44 & 28 & 33.76 & 27 & 78.13 & 19 \\
$\mathrm{C} 3$ & 0.65 & 2 & 8.81 & 14 & 12.64 & 24 & 27.35 & 25 & 30.11 & 21 & 70.76 & 16 \\
$\mathrm{C} 4$ & 0.65 & 3 & 9.64 & 3 & 10.56 & 11 & 24.94 & 11 & 18.58 & 14 & 47.00 & 10 \\
$\mathrm{C} 5$ & 0.66 & 1 & 9.35 & 3 & 5.98 & 9 & 16.92 & 12 & 19.75 & 11 & 49.56 & 15 \\
$\mathrm{C} 6$ & 0.67 & 2 & 8.85 & 8 & 3.45 & 12 & 16.89 & 12 & 19.29 & 12 & 52.77 & 9 \\
\hline
\end{tabular}


Table 3. Results of Tukey test to analyze influence of resin content factor

\begin{tabular}{cccccccc}
\hline Treatment & CE & MC & Dens & ST2H & ST24H & AA2H & AA24H \\
\hline \multirow{4}{*}{ CCA } & C1 & A & A & A & A & A & A \\
& C2 & A & A & AB & A & A & A \\
& C3 & A & A & B & A & A & A \\
\hline \multirow{4}{*}{ CCB } & C4 & A & A & A & A & A & A \\
& C5 & A & A & B & A & A & A \\
& C6 & A & A & B & A & A & A \\
\hline
\end{tabular}

From each panel, five specimens were obtained to determine density (Dens); moisture content (Mc); swelling in thickness after 2 (ST2h) and 24 (ST24h) hours; and water absorption after 2 (AA2h) and 24 hours (AA24h) of immersion, performing twenty specimens for each experimental condition. Tests were carryout according the EN 300 [9] Code, once a Brazilian normative document is not available yet.

The effects of resin content and preservative type on physical properties of OSB were investigated by analysis of variance (ANOVA). ANOVA and Tukey's test, evaluated at a $5 \%$ confidence level, were applied to identify and group the means between treatments. Results were compared with papers published by other researchers and requirements of EN 300 [9].

\section{Results and Discussion}

Table 2 present mean (M) results and coefficients of variation $(\mathrm{Cv})$ obtained for each treatment investigated.

It can be observed, in Table 2, that OSB mean density was slightly below the preconized density $0.70 \mathrm{~g} / \mathrm{cm}^{3}$. Such differences, according Iwakiri et al. [10] may be mainly related to operating conditions such as small losses of material during the formation of strand mattress and its pressing, besides the return on thickness of the panels after being removed from the press.

The Code EN 300 [9] does not report about moisture content, thickness swelling in $2 \mathrm{~h}$ and water absorption at 2 and $24 \mathrm{~h}$. So, results here obtained are compared to those found in literature.

Moisture content values obtained are satisfactory when compared to studies by Souza [8] which found mean values ranged between 8.2 and $10.3 \%$ for OSB panels manufactured with Pinus sp. and $12 \%$ of castor oil based polyurethane resin content.

In relation of properties as $\mathrm{ST} 2 \mathrm{~h}, \mathrm{AA} 2 \mathrm{~h}$ and $\mathrm{AA} 24 \mathrm{~h}$, results obtained in this research are consistent with those found by Surdi [11] for OSB panels with $0.67 \mathrm{~g} / \mathrm{cm}^{3}$ of density, whose values were 22.32 and $79 \%$, respectively.

Panels related $\mathrm{C} 1, \mathrm{C} 2$ and $\mathrm{C} 3$ conditions (CCA-treated panels) exceeded the limit of 25\% prescribed by EN 300 [9] standard, while panel related to C4, C5 and C6 (CCB-treated panels) conditions are in accordance with the values required by that standard for OSB type 2 (panels with structural application for dry conditions). It can be explained by the fact that molecules of CCA salts remain in cell walls and, difficult bonding reactions between resin and wood [2].

Coefficients of variation found for the physical properties here investigated are consistent with the results obtained by Souza [8].

Table 3 shows results of Tukey test conducted to verify the influence of resin content on physical properties. Means followed by same letter do not differ, in Tukey test.

It is observed in Table 3 that resin content only influencedinST2h property to CCA and CCB treated panels, and an increase in resin content significantly reduced ST2h.

This occurs due to the increased availability of resin per surface area of particles, which causes a decrease in water absorption with increasing resin content of 8 to $10 \%$. In this case, physical barrier (that is higher in the glue line) and occupancy of hygroscopic wood sites $(\mathrm{OH})$ leave the less reactive water panel [12].

Table 4 shows results for Tukey's test performed to check influence of the type of preservative treatment on the physical properties investigated.

Table 4. Results of Tukey test for factor analysis of the preservative treatment type factor

\begin{tabular}{ccccccc}
\hline \%Resin & \multicolumn{2}{c}{8} & \multicolumn{2}{c}{10} & \multicolumn{2}{c}{12} \\
\hline Treatment & CCA & CCB & CCA & CCB & CCA & CCB \\
\hline Dens. & A & A & A & A & A & A \\
MC & A & B & A & B & A & B \\
ST2H & A & B & A & B & A & B \\
ST24H & A & B & A & B & A & B \\
AA2H & A & B & A & B & A & B \\
AA24H & A & B & A & B & A & B \\
\hline
\end{tabular}

It is observed in Table 4 that the preservative treatment type influenced all properties analyzed. Panels treated with CCB preservative for all physical properties exhibited improved performance. The high values obtained of absorption and thickness swelling after 2 and 24 hours immersion for panels treated with CCA is possibly a consequence of the difficulty of adhesion between particles, since the cell walls already contain preservatives molecules that there lodged. Panels made with CCB showed better performance because the wood treated with this preservative has lower hygroscopicity due to their cells fill the preservative substances, thus decreasing the absorption of water. 


\section{Conclusions}

It is possible to conclude that $\mathrm{CCB}$ preservative is more feasible in treatment of wood for OSB manufactured, once panels reached consistent physical performance required by EN 300 for structural applications in dry environments, while CCA treated panels did not reach the minimum usage requirements stipulated by the mentioned Code.

Tukey's test for resin content showed that only thickness swelling after 2 hours of water immersion was influenced by this factor, and that increasing resin content provided reduction in the values of this property. Tukey's test for preservative treatment type showed that only density was not influenced by this factor and CCB treated panels presented better performance.

\section{REFERENCES}

[1] A. Cloutier, Oriented strand board (OSB): raw material, manufacturing process, properties and use, Proceedings of International Congress about Wood Products, Belo Horizonte, Brazil, 1998.

[2] F. S. Ferro, F. H. Icimoto, A. M. Souza, D. H. Almeida, A. L. Christoforo and F. A. Rocco Lahr, Production of Oriented Strand Board (OSB) with Schizolobium amazonicum and castor oil based polyurethane resin. Scientia Forestalis, 43, 313-320, 2015.

[3] S. Hiziroglu, Oriented Strand Board as a Building Material. Available in: http://pods.dasnr.okstate.edu/docushare/dsweb /Get/Document-3164/FAPC-145web.pdf. 1998.

[4] W.E. Currie, The environment advantages of using diffusible preservatives. In: The second International Conference on Wood Protection with Diffusible Preservatives and Pesticides. Forest Products Society. Madison, WI. pp. 33-41, 1997.
[5] G. J. Goroyias and M. D. Hale. The mechanical and physical properties of strand boards treated with preservatives at different stages of manufacture. Wood Science and Technology. 38, 93 - 107, 2004.

[6] M. S. Bertolini, Lahr, F. A. Rocco, M. F. Nascimento and J. A. M. Agnelli, Accelerated artificial aging of particleboards from residues of CCB treated Pinus sp. and castor oil resin. Materials Research, 16, 293-303, 2013.

[7] M. F. Nascimento, F. A. Rocco Lahr, M. S. Bertolini, A. M. Souza. Viabilidade do Emprego de Eucalyptus tratado com CCA e CCB na Produção de Painéis de Partículas de alta Densidade. In: Francisco Antonio Rocco Lahr; André Luís Christoforo. (Org.). Painéis de Partículas. 1ed. São Carlos: Escola de Engenharia de São Carlos, 1, 57-90, 2013.

[8] A. M. Souza, L. D. Varanda, L. B. Macedo, D. H. Almeida, M. S. Bertolini, A. L. Christoforo and F. A. Rocco Lahr, Mechanical Properties of OSB Wood Composites with Resin Derived from a Renewable Natural Resource. International Journal of Composite Materials, 4, 157-161, 2014.

[9] EN 300. Oriented Strand Boards (OSB): definitions, classification and specifications. Portugal, 2006.

[10] S. Iwakiri, C. E. C. Albuquerque, J. G. Prata and A. C. B. Costa. Utilization of wood of Eucalyptus grandis and Eucalyptus dunnii for Oriented Strand Board - OSB manufacturing. Ciência Florestal, 18, 265 - 270, 2008.

[11] P. G. Surdi, Production of oriented strand board (OSB) from hybrid of Pinus elliottii var. Elliottii x Pinus caribaea var. hondurensis. Piracicaba, 102 f. (Master's Dissertation, School Engineering of São Carlos, USP), 2012.

[12] L. M. Mendes, S. Iwakiri, J. L. M. Matos, S. Keinert Jr and L. K. Saldanha, Effects of panels density, composition, and resin content on OSB panels properties. Floresta e Ambiente, 10,457 - 468, 200363. 